\title{
Development of an Experimental Lunar Volatiles Extraction System
}

\author{
Aaron D.S. Olson \\ Fusion Technology Institute, Engineering Physics Dept., University of Wisconsin-Madison ${ }^{1}$
}

\begin{abstract}
The Helium Extraction \& Acquisition Testbed (HEAT) is an experimental lunar volatiles extraction system designed to test recuperative heat pipe heat exchanger (HPHX) technology that could be used to release volatiles from lunar regolith. HEAT has passive and active granular flow components that allow for the controlled flow of regolith through a variety of HPHX configurations. HEAT has instrumentation to measure regolith and heat pipe temperature at key positions in the device to ascertain the HPHX recuperative efficiency of the device. Volatile gas release is also measured with the use of a residual gas analyzer. The primary volatile of interest for this investigation is helium-3 $\left({ }^{3} \mathrm{He}\right)$. As a surrogate for ${ }^{3} \mathrm{He}$ containing regolith, ${ }^{4} \mathrm{He}$ containing JSC-1A regolith simulant is used. A summary of the design of the HEAT device and an overview of the modeling approach for an HPHX is discussed in this paper.
\end{abstract}

\section{Introduction}

The soil on the Moon has an abundance of volatiles that could be used for energy, fuel and life support for people in space. Water, hydrogen, oxygen, nitrogen, methane, carbon dioxide, carbon monoxide and helium isotopes are among the useful volatiles present. Hydrogen and methane can both be used as propellant in conjunction with oxygen. Water on the Moon can be electrolyzed to produce hydrogen and oxygen, or simply used for drinking water or plant growth (Metzger et al. 2013). The Fusion Technology Institute (FTI) at the University of Wisconsin-Madison has published research on the collection and potential use of helium-3 $\left({ }^{3} \mathrm{He}\right)$, starting in 1985 (Wittenberg et al. 1986; Wittenberg et al. 1992). If used in a nuclear fusion reactor, ${ }^{3} \mathrm{He}$ could potentially produce nuclear power without nuclear waste. ${ }^{3} \mathrm{He}$ is, however, scarce on the Earth (Wittenberg 1989). The U.S. government has reported $<30 \mathrm{~kg}$ of the gas available through its stockpiles (Kulcinski 2012). This amount would only be enough for $300 \mathrm{MW}$-yr of electricity from fusion. Samples from the Apollo program (missions 11, 12, and 14-17), along with the Soviet Luna 16 and 20 missions, indicate that the Moon has a large supply of ${ }^{3} \mathrm{He}$ due to solar wind bombardment. The solar wind, which is primarily composed of hydrogen $(\sim 96 \%)$ and helium-4 $\left({ }^{4} \mathrm{He}\right)(\sim 4 \%)$, also contains $\sim 0.002 \%{ }^{3} \mathrm{He}$. Over the lifetime of the Moon (4.5 billions of years), the solar wind has deposited over 500 million tonnes of ${ }^{3} \mathrm{He}$ onto the lunar surface. It has been estimated that $0.2 \%$ of this ${ }^{3} \mathrm{He}$ (one million tonnes) remains near the first 3 meters of the lunar surface (Wittenberg et al. 1986). Concepts and design work for robotic lunar mining systems to harvest lunar ${ }^{3} \mathrm{He}$ were published by the FTI, starting in 1988. The most recent work was completed in 2006 (Gajda 2006). This previous work has focused on an approach where excavated lunar regolith is sieved down to $<100 \mu \mathrm{m}$ and heated to $700^{\circ} \mathrm{C}$ in a recuperative heat pipe heat exchanger (Sviatoslavsky \& Jacobs 1988; Sviatoslavsky 1993; Gajda 2006). Heating the ${ }^{3} \mathrm{He}$ containing regolith to $700{ }^{\circ} \mathrm{C}$ has been shown to release $\approx 86 \%$ of the embedded ${ }^{3} \mathrm{He}$ (Pepin et al. 1970). Two of the mining system design iterations are illustrated in Figure 1.

\footnotetext{
${ }^{1}$ The work presented in this paper would not have been possible without the support of the Wisconsin Space Grant Consortium Graduate Fellowship Award and the NASA Space Technology Research Fellowship Program
} 

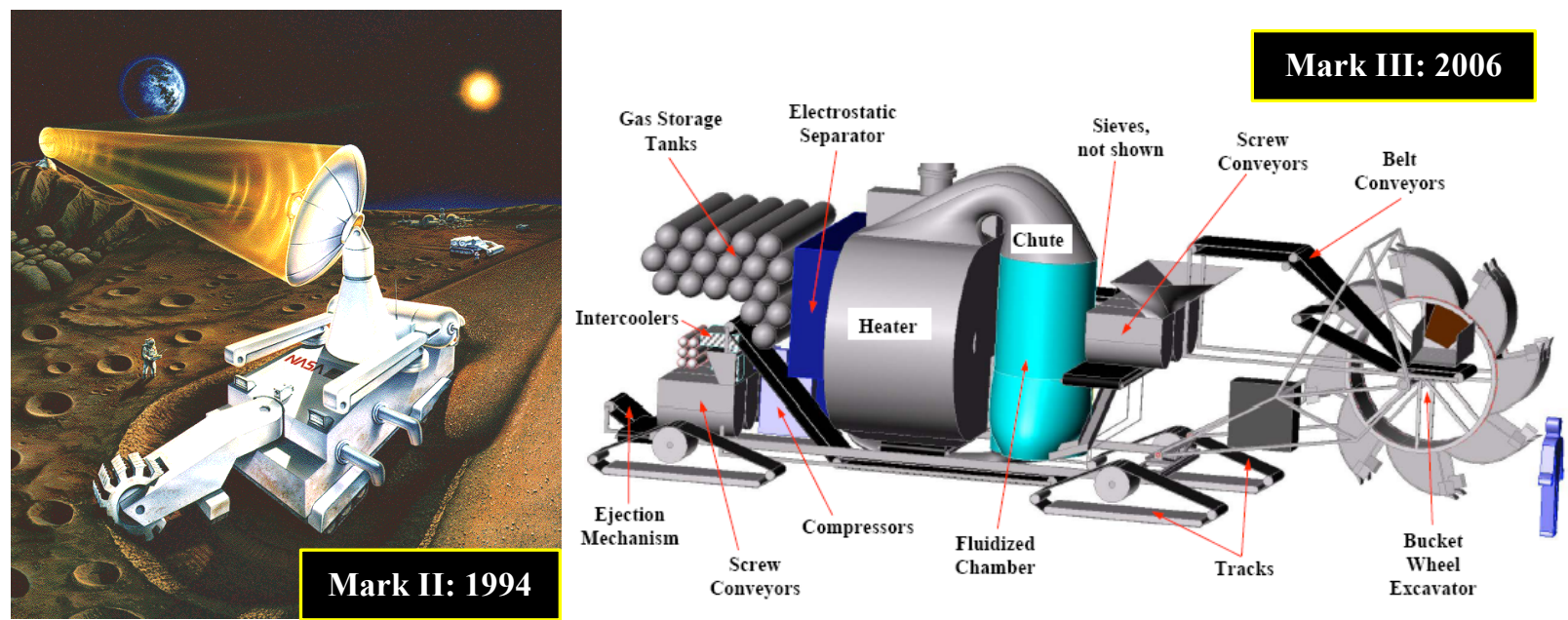

Figure 1. Fusion Technology Institute Mark-II Lunar ${ }^{3} \mathrm{He}$ miner (Sviatoslavsky 1993) (left, illustration by J. Andrews) and Mark-III miner (Gajda 2006) (right)

\section{Helium Extraction and Acquisition Testbed}

The Helium Extraction \& Acquisition Testbed (HEAT) is an experimental lunar volatiles extraction system designed to test recuperative heat pipe heat exchanger (HPHX) technology that could be used to release volatiles from lunar regolith. The advantage of using the HEAT system to extract volatiles, as opposed to a simpler heating system or furnace, is the system's ability significantly reduce the amount of thermal input energy required to heat regolith. This in turn reduces the total amount of mass required for a mining system, e.g., a solar thermal powered mining system could produce a given volatile output with a smaller, less massive parabolic dish.

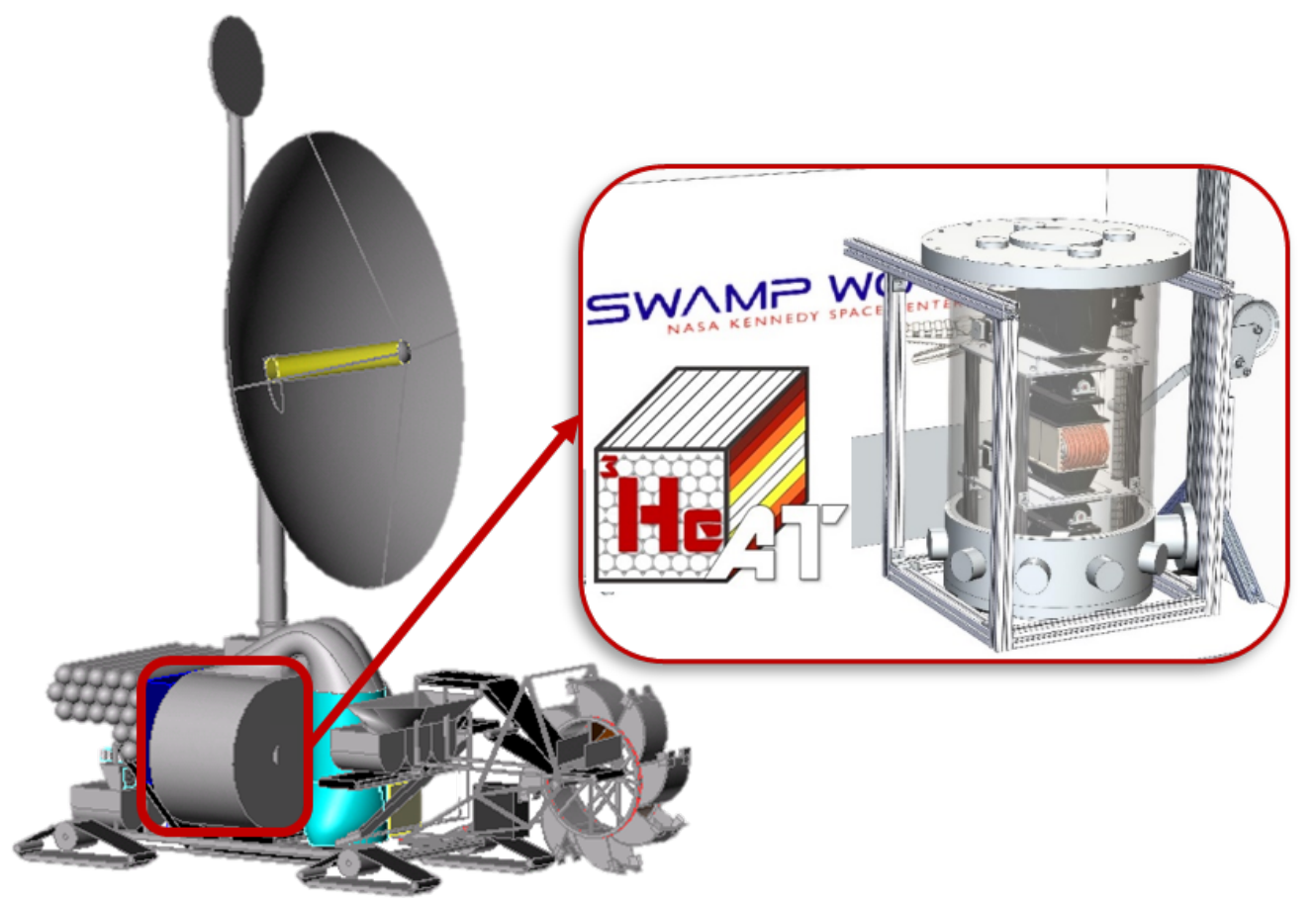

Figure 2. The HEAT system is a testbed for heat exchanger technology required for lunar solar wind volatiles systems like the Mark-3 Miner (credit: Gajda 2006) 
The first HPHX to be tested in HEAT is under construction. The data obtained from HEAT experiments will be compared to the expected gas release rates and thermal energy recuperative efficiencies of interchangeable HPHX configurations (Olson et al. 2014). Figure 2 illustrates the concept of the HEAT project and a model of the HEAT hardware inside of a vacuum chamber.

HEAT design and operation. The components of the HEAT system are designed to control the inlet and outlet flow of regolith simulant through a HPHX. These components include active and passive flow components, as illustrated in Figure 3. A set of hoppers hold $<100 \mu \mathrm{m}$ JSC-1A simulant at the top of the system. One of the hoppers contains ${ }^{4} \mathrm{He}$ implanted simulant, while the other contains un-implanted simulant. A dual slide gate valve below the hoppers allows for one of the hoppers to be discharged at a time. A rotary feeder sits below the dual slide gate valve. This feeder controls the inlet flow rate of simulant into a diffuser. The diffuser spreads the incoming simulant stream so that it is evenly spread across the width of the HPHX inlet. Simulant falls through the HPHX and into a funnel that rests atop a slide gate valve. This valve controls whether material can exit the HPHX. Below this gate valve is another rotary feeder that controls the outlet flow rate. Simulant processed in HEAT can have multiple passes through the HPHX. This is possible with the use of a 3 -way channel changer valve and two vertical screw conveyors. The channel changer valve can send material leaving the HPHX to an exit bin, or into one of two screw conveyors. One of which leads to the un-implanted hopper and the other leads to the implanted hopper.
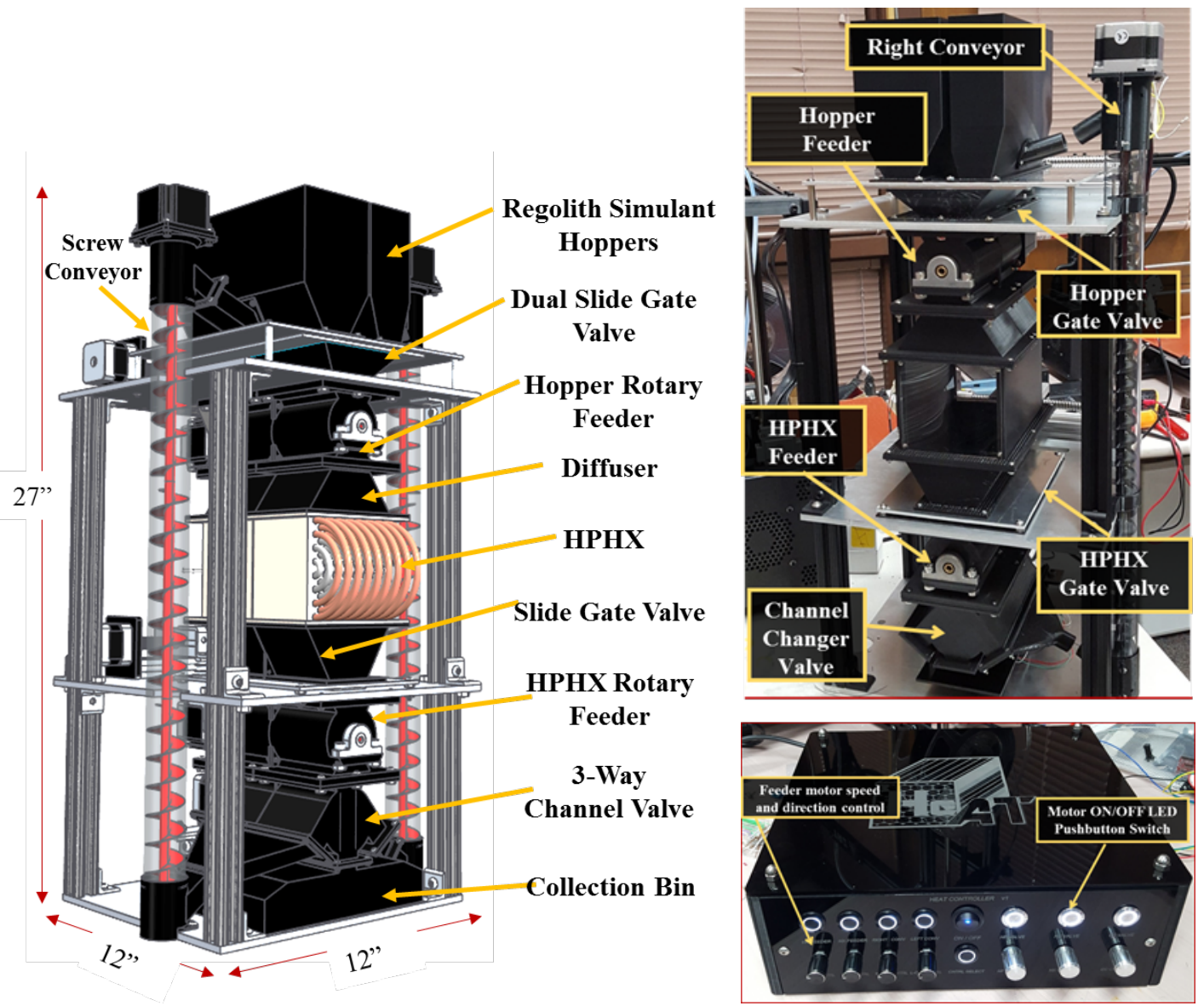

Figure 3. Model (left) and images (right) of the HEAT system's components 
There are two operational modes for the HEAT device. The first is the transient thermal mode. In this mode, un-implanted simulant is run through the HPHX until its heat pipes have reached their steady state temperatures. In the gas release mode, the un-implanted simulant is first returned to its hopper and then implanted simulant is run through the HPHX. An illustration of these operational modes is shown in Figure 4. Temperature and gas release rate measurements on a given HPHX configuration can be taken at prescribed flow rates to generate curves of thermal efficiency or gas release rate vs. mass flux. These curves can then be compared to the curves from the HPHX modeling approach described in the following section. The dimensions of the HPHX configurations can be at most $10.16 \mathrm{~cm}$ in height, $10.16 \mathrm{~cm}$ in width and $15.24 \mathrm{~cm}$ in depth, primarily due to size of the current vacuum chamber designated to house HEAT.

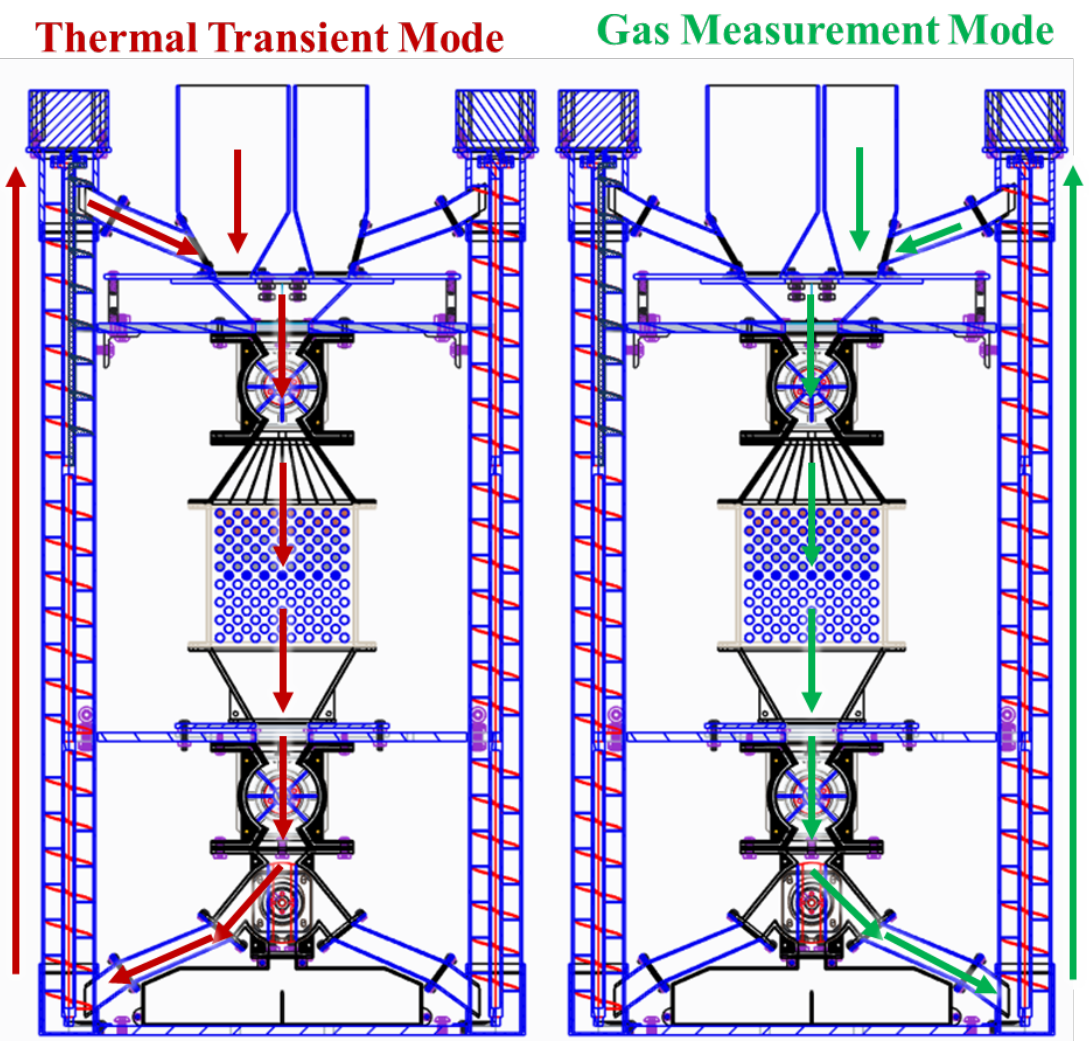

Figure 4. The two principal operational modes of the HEAT system

Heat pipe heat exchanger modeling. Heat pipe heat exchangers typically have multiple stages of heat pipes and are used to recuperate waste thermal energy in a number of industrial settings (Silverstein 1992). Heat exchanger analysis in general is based on an energy balance between a hot and cold stream of flowing material. The effectiveness ( $\varepsilon$ )-NTU equations are derived from this energy balance and can be used for heat exchanger design work (Nellis \& Klein 2009). Depending on the heat exchanger configuration (parallel, cross or counter flow), a different $\varepsilon$-NTU relation is used. The number of thermal transfer units (NTU) is a measure of a heat exchanger's total thermal conductance (UA) over its thermal capacitance rate ( $\dot{\mathrm{C}})$. A heat exchanger's (HX) effectiveness is a measure of how much of a temperature change the HX can provide. A heat pipe heat exchanger (HPHX) typically operates like a counter flow HX. A hot fluid flows over the evaporator section of heat pipes, while a cooler fluid flows over the condenser section. Silverstein has described the analysis of a multistage HPHX (Silverstein 1992). The heat transfer in each 
stage (row) of a HPHX is analyzed in two steps. The hot fluid flowing over the evaporator section first heats the heat pipe's working fluid, then the cold fluid flowing over the condenser section is heated by the condensing heat pipe working fluid. The thermal resistance of the thin metallic heat pipe vessel material is ignored in this analysis. The effectiveness of the evaporator, $\varepsilon_{\mathrm{H}}$, and condenser, $\varepsilon_{\mathrm{C}}$, sections is given in Eq. $1 . \mathrm{T}_{\mathrm{HI}}$ is the hot side inlet temperature, $\mathrm{T}_{\mathrm{HO}}$ is the hot side outlet temperature, $\mathrm{T}_{\mathrm{CI}}$ is the cold side inlet temperature, $\mathrm{T}_{\mathrm{CO}}$ is the cold side outlet temperature, and $T_{P}$ is the heat pipe's temperature.

$$
\varepsilon_{\mathrm{H}}=\frac{\mathrm{T}_{\mathrm{HI}}-\mathrm{T}_{\mathrm{HO}}}{\mathrm{T}_{\mathrm{HI}}-\mathrm{T}_{\mathrm{P}}}=1-\mathrm{e}^{-\mathrm{NTU}_{\mathrm{H}}} \quad \varepsilon_{\mathrm{c}}=\frac{\mathrm{T}_{\mathrm{CO}}-\mathrm{T}_{\mathrm{CI}}}{\mathrm{T}_{\mathrm{P}}-\mathrm{T}_{\mathrm{CI}}}=1-\mathrm{e}^{-\mathrm{NTU}_{\mathrm{C}}}
$$

The NTU in each section is described by Eq.2.

$$
\mathrm{NTU}_{\mathrm{H}}=\frac{\mathrm{h}_{\mathrm{H}} \mathrm{A}_{\mathrm{H}}}{\dot{\mathrm{C}}_{\mathrm{H}}} \quad \mathrm{NTU}_{\mathrm{C}}=\frac{\mathrm{h}_{\mathrm{C}} \mathrm{A}_{\mathrm{C}}}{\dot{\mathrm{C}}_{\mathrm{C}}}
$$

Where $h_{H}$ and $h_{C}$ are heat transfer coefficients at the evaporator and condenser sections, respectively. $A_{H}$ and $A_{C}$ are the surface areas of each section and $\dot{C}_{H}$ and $\dot{C}_{C}$ are the capacitance rates of the fluid flowing over each section. The capacitance rates are the product of the mass flow rate and specific heat. The rate of energy transfer between the two fluids must be equal as shown in Eq. 3. This allows for the calculation of the heat pipe temperature required for a prescribed change in hot and cold fluid temperatures, shown in Eq. 4.

$$
\begin{gathered}
\mathrm{Q}=\mathrm{C}_{\mathrm{H}}\left(\mathrm{T}_{\mathrm{HI}}-\mathrm{T}_{\mathrm{HO}}\right)=\mathrm{C}_{\mathrm{H}} \varepsilon_{\mathrm{H}}\left(\mathrm{T}_{\mathrm{HI}}-\mathrm{T}_{\mathrm{P}}\right)=\mathrm{C}_{\mathrm{C}}\left(\mathrm{T}_{\mathrm{CO}}-\mathrm{T}_{\mathrm{CI}}\right)=\mathrm{C}_{\mathrm{C}} \varepsilon_{\mathrm{C}}\left(\mathrm{T}_{\mathrm{P}}-\mathrm{T}_{\mathrm{CI}}\right) \\
\mathrm{T}_{\mathrm{P}}=\frac{\mathrm{T}_{\mathrm{HI}}+\mathrm{C}_{\mathrm{R}} \mathrm{E}_{\mathrm{R}} \mathrm{T}_{\mathrm{CI}}}{1+\mathrm{C}_{\mathrm{R}} \mathrm{E}_{\mathrm{R}}}
\end{gathered}
$$

The capacitance ratio, $C_{R}$, is the ratio of the cold stream capacitance rate to the hot stream capacitance rate. The effectiveness ratio, $\mathrm{E}_{\mathrm{R}}$, is the ratio of the condenser side effectiveness to the evaporator side effectiveness. For the case of a multistage $\mathrm{HPHX}$ with $\mathrm{N}$ stages where $\mathrm{E}_{\mathrm{R}}=1$, 
$\mathrm{C}_{\mathrm{R}}=1$, and each stage has the same effectiveness, the stage effectiveness can be found with Eq. 5. This situation is particularly relevant to the HEAT system.

$$
\varepsilon_{\mathrm{ST}}=\frac{2 \varepsilon}{\mathrm{N}-(\mathrm{N}-1) \varepsilon}
$$

The overall heat transfer area required for a given stage is then shown in Eq. 6 .

$$
\mathrm{A}_{\mathrm{ST}}=\left(\mathrm{A}_{\mathrm{H}}+\mathrm{A}_{\mathrm{C}}\right)=\frac{2 \dot{\mathrm{C}}\left(\mathrm{NTU}_{\mathrm{S}}\right)}{\mathrm{h}_{\mathrm{H}}}
$$

For this HPHX configuration the temperature of each stage of heat pipes is then simply the average of the hot and cold stream inlet temperatures, as shown in Eq. 7.

$$
\mathrm{T}_{\mathrm{P}}=\frac{\mathrm{T}_{\mathrm{HI}}+\mathrm{T}_{\mathrm{CI}}}{2}
$$

The change in temperature of each stream of fluid through one stage is then found to be the product of the stage effectiveness and the difference in temperature between the cold inlet and the heat pipe stage temperature (which is the same as the difference in temperature between the hot inlet and the heat pipe stage as well). This relationship is shown in Eq. 8.

$$
\Delta \mathrm{T}_{\mathrm{ST}}=\varepsilon_{\mathrm{ST}}\left(\mathrm{T}_{\mathrm{P}}-\mathrm{T}_{\mathrm{CI}}\right)=\varepsilon_{\mathrm{ST}}\left(\mathrm{T}_{\mathrm{HI}}-\mathrm{T}_{\mathrm{P}}\right)
$$

The heat rate (power) that each heat pipe in a stage of the HPHX must transfer can then be calculated as shown in Eq. 9 where $\mathrm{N}_{\mathrm{Col}}$ is number of pipes in a stage.

$$
\mathrm{Q}=\frac{\dot{\mathrm{C}} \varepsilon_{\mathrm{ST}} \Delta \mathrm{T}_{\mathrm{ST}}}{\mathrm{N}_{\mathrm{Col}}}
$$

The heat pipes in each stage must be designed to operate at their stage temperature and with the fraction of the total heat rate for their stage that they provide. The working fluid within the heat pipes is determined by the operating temperature and the vessel material must be compatible with the fluid at the selected temperature. From $5^{\circ}-230^{\circ} \mathrm{C}$, water can be used as the working fluid with copper tubes $\left(\mathrm{Cu}-\mathrm{Ni}\right.$ alloys can also be used). From $190^{\circ}-550^{\circ} \mathrm{C}$, mercury can be used with stainless steel pipes. From $300^{\circ}-600^{\circ} \mathrm{C}$, Cesium can be used with nickel alloys (like Inconel) or stainless steel. From $400^{\circ}-800^{\circ} \mathrm{C}$, Potassium can be used with nickel alloys or stainless steel. From $500^{\circ}-900^{\circ} \mathrm{C}$, sodium can be used with nickel alloys or stainless steel (Reay 2006).

The heat transfer coefficient between the heat pipes and the flowing material in an HPHX determines the amount of surface area required for a given HPHX stage. Niegsch developed and validated a model that describes the velocity field and the local and average heat transfer coefficients between pipes in moving bed heat exchangers (Niegsch et al. 1994). The model considers the stagnation zones and voids created when bulk solids flow over tubes as shown in Figure 5. 

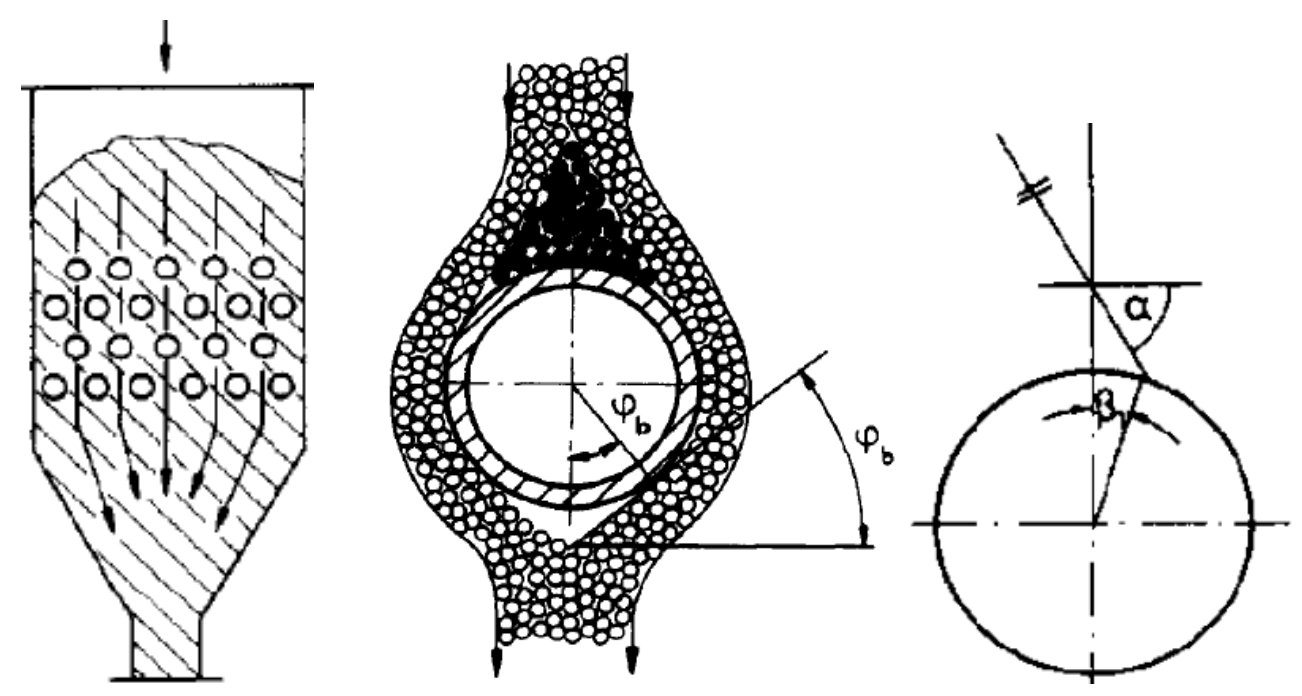

Figure 5. Flow of granular material across a matrix of pipes and the characteristic angles defining the channeling of material flow (credit: Niegsch et al. 1994)

The frictional properties of the granular material and the tube walls determine the shape of the flow channel. There appears to be a cuneiform resting or stagnation zone that is created when a bulk solid flow occurs over a circular pipe. The slope of the stagnation layer can be approximated as shown in Eq. 10.

$$
\alpha=\frac{\pi}{4}+\frac{\varphi_{\mathrm{e}}}{2}
$$

The effective angle of friction, $\varphi_{\mathrm{e}}$, can be measured from shear cell tests of the granular material. The termination of the stagnation layer is described by the angle $\beta$, which can be calculated as shown in Eq. 11.

$$
\beta=\frac{1}{2}\left[\cos ^{-1}\left(\frac{1-\sin \left(\varphi_{\mathrm{e}}\right)}{2 \sin \left(\varphi_{\mathrm{e}}\right)}\right)+\sin ^{-1}\left(\frac{\sin \left(\varphi_{\mathrm{w}}\right)}{\sin \left(\varphi_{\mathrm{e}}\right)}\right)+\varphi_{\mathrm{w}}\right] \quad \text { if } \beta<\alpha
$$

The effective angle of wall friction, $\varphi_{\mathrm{w}}$, can also be obtained from shear cell tests of the granular material and specific wall material. If $\beta$ is calculated to be larger than $\alpha, \beta$ is taken to simply be $\alpha$, since this is the largest physically possible value for the stagnation termination layer angle. The void or bubble zone around a pipe can be described with the angle of repose, $\varphi_{b}$, of a granular material. These three angles are illustrated in Figure 5. Three distinct flow sections are considered in the Niegsch model. Section I is the stagnation flow section, section II is the flow that directly touches the sides of the tubes. Section III is the flow that touches the void zone below the pipes. The three sections are shown in Figure 6. The calculation of the velocity field in each of the sections adheres to the following assumptions:

- Symmetric flow across the z-axis

- 2D flow: no change in the x-direction

- The flow only has a radial component in each calculation zone

- Steady flow

- The granular material is described as a continuum fluid that is isotropic and incompressible 
Sections I and III of the flow model have constant wall angles, $\theta_{\mathrm{w}, \mathrm{I}}$ and $\theta_{\mathrm{w}, \mathrm{III}}$, but section II has variable wall angles as the angle around the circumference of the tubes changes. By discretizing section II into a set of funnel-like flow zones, a solution for the entire flow channel can be found. The velocity field, which is the radial velocity in terms of $r$ and $\theta$, is shown in Eq. 12. The inlet flow velocity is $U_{0}$ and the radial distance between the origin of the cylindrical and cartesian coordinate systems is $\mathrm{z}^{*}$. The parameter $\mathrm{k}$ is described in Eq. 13, where $\theta_{\mathrm{w}}$ is the local wall angle.

$$
\begin{gathered}
\mathrm{u}_{\mathrm{r}}(\mathrm{r}, \theta)=\frac{\mathrm{U}_{0} \mathrm{z}^{*}}{\mathrm{r}}[\cos (2 \mathrm{k} \theta)]^{\frac{1}{\mathrm{k}}} \\
\mathrm{k}=\left(\varphi_{\mathrm{w}}+\sin ^{-1}\left(\frac{\sin \left(\varphi_{\mathrm{w}}\right)}{\sin \left(\varphi_{\mathrm{e}}\right)}\right)\right)\left(\frac{1}{2 \theta_{\mathrm{w}}}\right)
\end{gathered}
$$

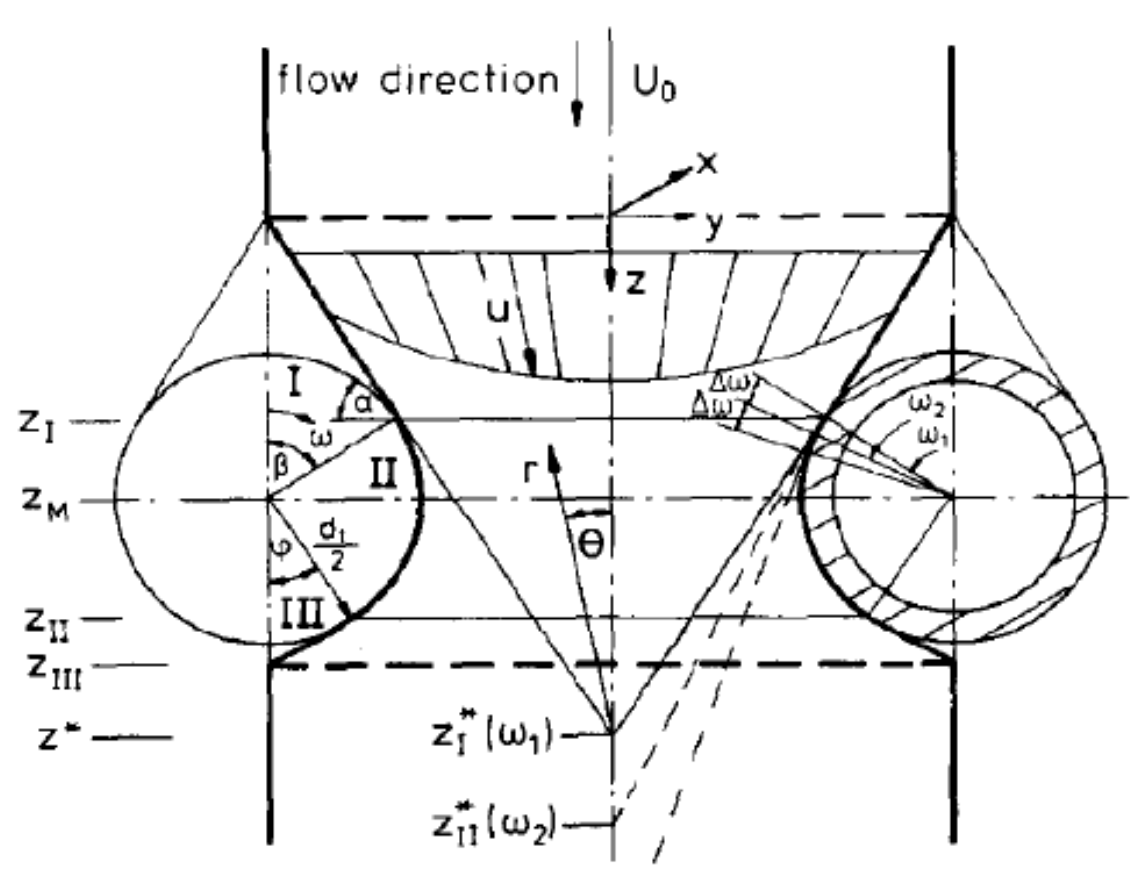

Figure 6. Three segment flow channel according to the Niegsch model

The thermal resistance between the outer surface of a pipe and the bulk material depends on the section. In section I there are three resistances to consider; the wall surface resistance, a stagnation layer insulation resistance, and a bulk solid thermal penetration resistance. In section II the insulation resistance does not apply. In section III, the insulation and wall surface resistances do not apply, but there is an additional resistance due to the convective heat transfer between the gas in the void zone to the moving bulk material. The wall surface resistance can be described by the heat transfer coefficient shown in Eq. 14. 


$$
h_{w s}=\varphi_{s c} h_{w p}+\left(1-\varphi_{s c}\right)\left(\frac{\frac{2 k_{g}}{d_{p}}}{\sqrt{2}+\frac{2\left(l_{0}+\delta\right)}{d_{p}}}\right)
$$

The surface coverage factor, $\varphi_{\mathrm{sc}}$, describes how completely the wall surface can be covered by the particles being considered. The thermal conductivity of the interstitial gas is $\mathrm{k}_{\mathrm{g}}$. The mean particle diameter is $d_{p}$. The modified mean free path of the interstitial gas particles is $1_{0}$. The wall surface roughness is $\delta$. The heat transfer to individual particles in contact with the tube wall, $\mathrm{h}_{\mathrm{wp}}$, can be determined from Eq. 15.

$$
\mathrm{h}_{\mathrm{wp}}=\frac{4 \mathrm{k}_{\mathrm{g}}}{\mathrm{d}_{\mathrm{p}}}\left[\left(1+\frac{2 \mathrm{l}_{0}}{\mathrm{~d}_{\mathrm{p}}}\right) \ln \left(1+\frac{\mathrm{d}_{\mathrm{p}}}{2 \mathrm{l}_{0}}\right)-1\right]
$$

The bulk thermal penetration resistance can be described with Eq. 16 where the bulk material density, $\rho$, specific heat, $\mathrm{c}$, thermal conductivity, $\mathrm{k}$, are used as well as the contact time of the material at the tube wall, $\mathrm{t}_{\mathrm{c}}$.

$$
\mathrm{h}_{\mathrm{so}}=2 \sqrt{\frac{\rho \mathrm{ck}}{\pi \mathrm{t}_{\mathrm{c}}}}
$$

The bulk thermal penetration resistance and the wall surface resistance have the largest effect on the overall heat transfer between a pipe and flowing bulk material, however, relationships for the insulation and convective resistances can be found in (Niegsch et al. 1994). The model has also been compared to Eulerian two phase computational fluid dynamics (CFD) simulations of granular flow between pipes, in Ansys Fluent ${ }^{\circledR}$, by Baumann and Zünft. This work was related to heat exchangers for concentrating solar power plants(Baumann \& Zunft 2012; Baumann et al. 2013; Baumann et al. 2014). Baumann and Zünft also compared the Niegsch et al. model and their CFD simulations to experimental results, collected by means of particle image velocimetry, with good agreement.

\section{Conclusion}

The Helium Extraction \& Acquisition Testbed (HEAT) has been developed to test recuperative heat pipe heat exchanger (HPHX) technology that could be used to release volatiles from lunar regolith. The HEAT hardware allows for the integration of various HPHX configurations. These configurations are designed with the previously described multistage HPHX and granular flow modeling approach.

\section{Acknowledgements}

- Wisconsin Space Grant Consortium Graduate Fellowship Program

- NASA Space Technology Fellowship Program

- Prof. Gerald L. Kulcinski, University of Wisconsin-Madison, Engineering Physics Dept.

- Prof. John F. Santarius, University of Wisconsin-Madison, Engineering Physics Dept.

- Dr. James Mantovani, NASA Kennedy Space Center Swamp Works Labs 


\section{References}

Baumann, T. \& Zunft, S., 2012. Theoretical and experimental investigation of a Moving Bed Heat Exchanger for Solar Central Receiver Power Plants. In European Thermal Sciences Conference.

Baumann, T., Zunft, S. \& Tamme, R., 2014. Moving Bed Heat Exchangers for Use With heat Storage in Concentrating Solar Plants: A Multiphase Model. Heat Transfer Engineering, 35(3), pp.224-231.

Baumann, T., Zunft, S. \& Tamme, R., 2013. Moving Bed Heat Exchangers for Use With Heat Storage in Concentrating Solar Plants: A Multiphase Model. Heat Transfer Engineering, 35(3), pp.224-231. Available at: http://www.tandfonline.com/doi/abs/10.1080/01457632.2013.825154 [Accessed March 18, 2015].

Gajda, M., 2006. A Lunar Volatiles Miner. University of Wisconsin-Madison, M.S. Thesis. Available at: http://fti.neep.wisc.edu/pdf/fdm1304.pdf.

Kulcinski, G.L., 2012. Fusion Fuel Resources. In UW-Madison, NEEP-536 Course Lecture 6, Sept. 20, 2012. p. 20.

Metzger, P.T. et al., 2013. Affordable, Rapid Bootstrapping of the Space Industry and Solar System Civilization. Journal of Aerospace Engineering, 26(1), pp.18-29. Available at: http://ascelibrary.org/doi/abs/10.1061/\%28ASCE\%29AS.1943-5525.0000236 [Accessed January 23, 2013].

Nellis, G. \& Klein, S., 2009. Heat Exchangers. In Heat Transfer. p. 857.

Niegsch, J., Koneke, D. \& Weinspach, P.M., 1994. Heat transfer and flow of bulk solids in a moving bed. Chemical Engineering and Processing, 33, pp.73-89.

Olson, A.D.S., Santarius, J.F. \& Kulcinski, G.L., 2014. Design of a Lunar Solar Wind Volatiles Extraction System. In AIAA SPACE 2014 Conference and Exposition. Available at: http://arc.aiaa.org/doi/abs/10.2514/6.2014-4234 [Accessed August 25, 2014].

Pepin, R.O. et al., 1970. Rare Gases in Apollo 11 Lunar Material. In Proceedings of the Apollo 11 Lunar Science Conference. pp. 1435-1454.

Reay, D.A., 2006. Heat Pipes 6th ed., Oxford: Butterworth-Heineman.

Silverstein, C., 1992. Heat Pipe Heat Exchangers. In Design and Technology of Heat Pipes for Cooling and Heat Exchange. Philadelphia: Taylor and Francis Ltd., pp. 221-246.

Sviatoslavsky, I.N., 1993. The Challenge of Mining He-3 on the Lunar Surface: How All the Parts Fit Together. In Space 94, The 4th International Conference and Exposition on Engineering, Construction and Operations in Space, and The Conference and Exposition/Demonstration on Robotics for Challenging Environments, February 26 - March 3, 1994, Albuquerque NM Also: WCS.

Sviatoslavsky, I.N. \& Jacobs, M.K., 1988. Mobile Helium-3 Mining and Extraction System and Its Benefits Toward Lunar Base Self-Sufficiency. In Wisconsin Center for Space Automation and Robotics Technical Report (WCSAR-TR) AR3-8808-1. Available at: http://fti.neep.wisc.edu/pdf/wcsar8808-1.pdf.

Wittenberg, L.J. et al., 1992. A Review of Helium-3 Resources and Acquisition for Use as Fusion Fuel. Fusion Technology, 21, pp.2230-2253.

Wittenberg, L.J., 1989. Terrestrial Sources of Helium-3 Fusion Fuel- A Trip to the Center of the Earth. Fusion Technology, 15, p.1108. Available at:http://fti.neep.wisc.edu/pdf/fdm769.pdf.

Wittenberg, L.J., Santarius, J.F. \& Kulcinski, G.L., 1986. Lunar Source of 3He For Commercial Fusion Power. Fusion Technology, 10, pp.167-178. 